\title{
KULEUVEN
}

DEPARTMENT OF ECONOMICS

\section{Who is afraid of Bayesian persuasion?}

Luc LAUWERS and Patrick VAN CAYSEELE

FACULTY OF ECONOMICS AND BUSINESS

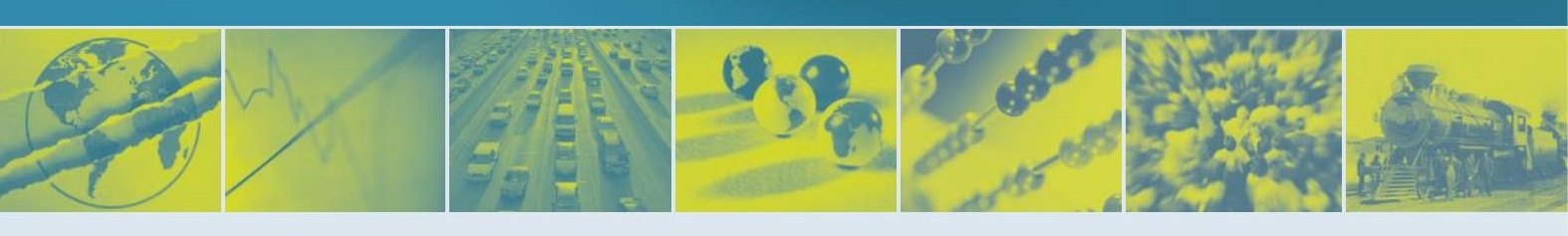

DISCUSSION PAPER SERIES DPS18.05

JUNE 2018 


\title{
Who is afraid of Bayesian persuasion?
}

\author{
Luc Lauwers · Patrick Van Cayseele \\ e-mail: luc.lauwers@kuleuven.be,patrick.vancayseele@kuleuven.be \\ Katholieke Universiteit Leuven, Department of Economics \\ Naamsestraat 69, 3000 Leuven, Belgium
}

April 18, 2018

\begin{abstract}
Bayesian persuasion (Kamenica and Gentzkow 2011) refers to the optimal signalling of a Sender with informational advantage over the Receiver, under the constraint that the expected posterior (over the state space) equals the common prior. In the basic example of a judicial system with a prosecutor (Sender) and a judge (Receiver) who needs to convict or acquit a defendant, the mechanism of Bayesian persuasion entails the detriment of the third party (absent in the model): innocent subjects who get convicted suffer from this optimal signalling scheme. If the judge is concerned about errors of convicting innocent defendants, or about the overall sustainability of the judicial system, outcomes different from Kamenica and Gentzkow (2011) may arise.
\end{abstract}

Keywords. Bayesian persuasion, Blackstone ratio. 


\section{Introduction}

Kamenica and Gentzkow (2011, henceforth KG) study a male Sender who wishes to persuade a female Receiver to take an action that he prefers over the action she was originally going to take. Their leading example considers a judge (Receiver) who receives a signal from the prosecutor (Sender). The judge has to choose between convicting or acquitting a defendant. The prosecutor prefers (and tries to persuade) the judge to convict. ${ }^{1}$ Their motivating question (KG p2590) reads:

When is it possible for one person to persuade another to change her action?

KG ensure the prosecutor and the judge share a prior belief that 30 percent of the defendants are guilty. Hence, if the prosecutor chooses a fully informative investigation, one that leaves no uncertainty about being innocent or guilty, the judge convicts 30 percent of the defendants. Their analysis, however, shows that the prosecutor can do better. The optimal Bayesian persuasion mechanism entails that the judge convicts with probability 60 percent. Hence,

the judge knows 70 percent of defendants are innocent, yet she convicts 60 percent of them! She does so even though she is fully aware that the investigation was designed to maximize the probability of conviction.

(KG p2591)

This is a frightening conclusion. The gap between the ex ante position (30 percent of the defendants are guilty) and the outcome (60 percent of the defendants are convicted) is, we believe, hard to defend in view of a legal system that serves the functioning of a community. A judicial system that convicts about 30 out of 70 innocent defendants seems harmful for society.

The KG outcome definitely conflicts with a long tradition in criminal law prescribing that minimizing wrongful convictions is more important than overall accuracy. Fallon (2008 p1706) summarizes this idea as follows:

\footnotetext{
${ }^{1}$ The bank sector provides an alternative story. A bank is either solvent or insolvent. A depositor (Receiver) has to decide about leaving or staying with the bank. A regulator (Sender) prefers the depositor to stay.
} 
[E]rrors that result in the conviction of the innocent are more morally disturbing than errors that result in acquittals of the guilty. In light of that assessment, we have adopted a system that minimizes the most morally grievous errors, even if that system leads to more of the less grievous errors, and indeed to more total errors, than would an alternative.

The idea is linked to a statement by Blackstone:

Better that ten guilty persons escape, than that one innocent suffer.

Although Blackstone's maxim dates from 1765, it is still used to convey the message quickly and memorably.

Inspired by this tradition in criminal law, we modify the preferences of the judge to include aversion for convicting-innocent errors. This intervention (within the Bayesian persuasion model) decreases the gap between the outcome and the ex ante position towards a more sustainable level. A decrease in the gains for the prosecutor from using probability inflated signals on innocents is an additional consequence of our modification.

The next section introduces the KG model. For simplicity we stay within the numerical example of KG. Section 3 shortly discusses some negative consequences of the KG outcome. Section 4 modifies, in the spirit of Blackstone's principle, the preferences of the judge. Section 5 closes.

\section{Bayesian Persuasion}

We introduce the judge-prosecutor example of KG. The judge (she) has to choose between convicting or acquitting a defendant. There are two states of the world: the defendant is either guilty or innocent. The prosecutor and the judge share a prior belief that 30 percent of the defendants are guilty and 70 percent are innocent. Let us denote this common prior by $\operatorname{Prob}($ guilty $)=.3$. The preferences of the prosecutor and the judge are as follows. The judge gets utility 1 for choosing the just action (convicting if guilty, and acquitting if innocent) and utility 0 for choosing the unjust action. The utility of the prosecutor is either 0 or 1 depending upon whether the defendant is declared to be innocent or guilty. 
A legal system that succeeds in rendering the best possible judicial outcome would result in the following outcomes or decisions (where $i$ and $g$ stand for being declared innocent and guilty), the probabilities of which are denoted by $D$ :

$$
\begin{array}{ll}
D(i \mid \text { innocent })=1, & D(i \mid \text { guilty })=0, \\
D(g \mid \text { innocent })=0, & D(g \mid \text { guilty })=1 .
\end{array}
$$

With probability 1 an innocent defendant is declared innocent, and so forth. The above scheme will show up in the case that the prosecutor chooses (and is able to perform) a fully informative investigation that leaves no uncertainty about the state of the world. The distribution of the outcomes coincides with the prior. The proportion of defendants declared guilty is equal to the proportion of defendants being guilty. The expected payoffs for the judge and the prosecutor are equal to 1 and .3 .

KG show that, in the Bayesian persuasion setting, the prosecutor can improve his payoff. More precisely, the uniquely optimal outcome entails:

$$
\begin{array}{ll}
D(i \mid \text { innocent })=4 / 7, & D(i \mid \text { guilty })=0 \\
D(g \mid \text { innocent })=3 / 7, & D(g \mid \text { guilty })=1 .
\end{array}
$$

Now, with probability 4/7 an innocent defendant is declared innocent. All the prosecutor needs to do, is to signal a .5 probability of being guilty for 60 percent of the defendants. More precisely, he will signal .5 probability of being guilty for the 30 (out of 100) defendants that are guilty and .5 probability of being guilty for 30 (out of the remaining 70 ) innocent defendants.

KG present the above conditional probabilities $D$ as a signalling scheme denoted by $\pi$. The prosecutor communicates either $i$ or $g$. The judge, when receiving $g$, uses the signalling scheme $\pi=D$ and updates her beliefs to

$$
\operatorname{Prob}(\text { guilty } \mid g)=\frac{\operatorname{Prob}(\text { guilty and } g)}{\operatorname{Prob}(g)}=\frac{.3}{1 \times .3+\frac{3}{7} \times .7}=.5 \text {. }
$$

We abbreviate this argument and we just write that the prosecutor signals that the defendant is guilty with .5 probability.

When the judge receives this signal of .5 probability of guilt, she rules the defendant guilty. Indeed, in this case, her expected utility of .5 does not depend on her action (convicting 
and acquitting). Being indifferent, she selects the action that maximizes the prosecutors payoff, and she chooses to convict the defendant. If the judge receives a signal of less than .5 probability of guilt, she declares the defendant not guilty. This leads to the above decision scheme (denoted by $D$ ). The prosecutor does not violate the coincidence of the prior and the expected posterior. Indeed, the .5 probability degree of guilt for 60 percent of the defendants results in an expectation of .3 probability of being guilty.

KG show that the above signalling scheme is the unique maximizer of the sender's payoff in the constrained optimization problem. The realized payoff for the sender doubles (from .3) to .6. The constraint, that the expected posterior equals the common prior, is met.

In conclusion, the Bayesian persuasion model enforces the judge to convict 60 percent of the defendants, about half of them possibly being innocent. Nevertheless, she has full information of the mechanism and of the optimal strategy of the prosecutor.

An update of the common prior of being guilty from .3 towards .6 (the observed outcome) is not appropriate. The Bayesian persuasion model applied to a prior of .6 entails the optimal (ex post) outcome in which all defendants will be declared guilty. Indeed, the sender will always signal .6 probability of being guilty. The update of the prior further widens the gap between the ex ante and the ex post positions.

\section{Absent third party and social costs}

The above KG-model does not take all involved parties into account. The subjects that undergo the legal system form an absent third party. They observe (undergo) the game, the rules of the game, and the outcome. The huge difference between the prior and the outcome seems unacceptable. The public might loose confidence in the legal system. In other words, the defendants should not remain outside the decision making process in order to avoid contracting in their absence. ${ }^{2}$

Next, the social cost of this Bayesian persuasion game is high. In the numerical example of $\mathrm{KG}$, about twice the people that should be incarcerated effectively go to prison. Since

\footnotetext{
${ }^{2}$ In a different framework, Aghion and Bolton (1987) argue that an incumbent may contract with a consumer disfavoring a potential entrant when he remains out of the negotiations.
} 
sentencing to jail creates high costs for society (McDougall et al. 2003), this could lead to further undesirable consequences. Judges realize that, given the information structure, they make errors and may start giving shorter sentences than necessary relative to what a truly guilty subject should receive. Or, political pressure on budgets might lead to the same outcome (Clark and Lee 1996). In the end, the entire judicial system might collapse. People circumvent the judicial system and take the law into their own hands.

\section{Omission-commission bias}

The judge faces the following errors or unjust decisions: convicting an innocent defendant, and acquitting a guilty one. In KG, the judge follows the prosecutor's signal and is forced to make "convicting-innocent" errors. Below we modify the preferences of the judge. In particular, we equip the judge with an aversion for convicting-innocent errors.

We consider two types of judges. The commission-biased judge is still willing to make decisions and to convict defendants, but she tries to lower the convicting-innocent errors. The omission-biased judge dismisses the trial (by declaring each defendant not-guilty). She keeps her hands clean by referring the trial to an entirely different decision making authority.

\subsection{Blackstone ratio}

In criminal law, the ratio "ten" guilty persons who escape to "one" innocent who is punished, is known as the Blackstone ratio. Predecessors of Blackstone, have proposed a ratio of twenty (Fortescue 1471) or five (Hale 1678). ${ }^{3}$ A recent experimental study of Dutch community views about the Blackstone ratio revealed $(i)$ a preference for ratios larger than five, and $(i i)$ that the ratio decreases as the seriousness of the offence increases (de Keijser et al. 2014).

We introduce the dislike of making errors in the KG model by changing the objective of the judge. Instead of maximizing the expected number of just/right decisions, she could minimize the expected sum of errors with more weight attached to the convicting-innocent

\footnotetext{
${ }^{3}$ Laudan $(2006$, p63) lists some of the historical opinions about this issue.
} 
errors:

$$
\text { minimize } \alpha \cdot D(g \mid \text { innocent }) \cdot \operatorname{Prob}(\text { innocent })+D(i \mid \text { guilty }) \cdot \operatorname{Prob}(\text { guilty })
$$

with $\alpha$ the weight she attaches to the convicting-innocent error. The first term in the objective function presents the expected number of convicting-innocent errors multiplied by $\alpha$, the second term is the expected number acquitting-guilt errors. The case $\alpha=1$ returns the original KG example. If $\alpha>1$, then the judge dislikes the convicting-innocent error more than the acquitting-guilt error. The case $\alpha=10$ corresponds to the original Blackstone ratio: the above objective function, then, considers one convicting-innocent error and ten acquitting-guilt errors equally bad.

Within the Bayesian persuasion model, this modification affects the optimal signalling strategy of the prosecutor. In order to make the judge indifferent between acquitting and convicting, he signals a probability degree of guilt equal to $\alpha /(1+\alpha)$ for the 30 guilty defendants and for $30 /(70 \alpha)$ of the 70 innocent defendants. The expected posterior reads

$$
.3 \frac{\alpha}{1+\alpha}+.7 \frac{30}{70 \alpha} \frac{\alpha}{1+\alpha}=.3
$$

and coincides with the common prior $\operatorname{Prob}($ guilty $)=.3$. The constraint the prosecutor faces is met, and his expected payoff decreases from .6 to $.3(1+1 / \alpha)$. In the optimal outcome, given by

$$
\begin{array}{ll}
D(i \mid \text { innocent })=1-\frac{3}{7 \alpha}, & D(i \mid \text { guilty })=0 \\
D(g \mid \text { innocent })=\frac{3}{7 \alpha}, & D(g \mid \text { guilty })=1
\end{array}
$$

the amount of convicting-innocent errors reduces (assume $\alpha>1$ ) to $3 /(7 \alpha)$. An increase in $\alpha$, entails a decrease in the gains for the prosecutor due to the probability inflated signals on innocents. The conservative case $\alpha=5$ entails that the prosecutor uses a signal of .83 probability of guilt. The KG model, then, presupposes that the prosecutor is able to assign this guilt probability of .83 to about 9 percent of the innocent defendants. ${ }^{4}$ Finally, when $\alpha$ is large, the judge almost asks the prosecutor for a full proof of guilt before she convicts the defendant.

\footnotetext{
${ }^{4}$ It is not clear whether this assumption is realistic.
} 
In sum, the judge dislikes convicting-innocent errors and incorporates this concern in her preferences. She still knows that the mechanism entails errors when taking decisions. She is commission biased in the sense that she insists on taking decisions (convicting or acquitting a defendant). With a Blackstone ratio of five and if the assumptions of KG do hold, then the percentage of convicting-innocent errors decreases from $43 \%$ to $9 \%$ and the optimal payoff for the prosecutor decreases from .6 to .36. This modification narrows down the gap between the outcome (36 percent of the defendants are convicted guilty) and the ex ante prior (30 percent of the defendants are guilty). ${ }^{5}$

\subsection{Clean hands, justice outside the court}

Until now, focus was on the sender-preferred subgame perfect equilibria. In the above examples, a judge indifferent to either convicting or acquitting maximizes the prosecutor's payoff. In this way, the judge, who minimizes the expected weighted sum of errors, obtains an optimal (minimal) payoff equal to .3 .

The judge, however, can realize the same payoff by declaring each defendant not-guilty. One can interpret this behavior as a judge who is unwilling to make decisions. For example, the judge decides that her court is not ceased by the alleged felony that has taken place and dismisses the case, or starts postponing judgments by asking pre-judicial questions to higher courts. In the latter case, the higher court usually only takes into consideration procedural issues or legal formalistic considerations, and does not look at the facts. In the first case, the facts might not receive proper attention if, for instance, the case becomes a media trial.

Again, the judge might dislike convicting-innocent errors, but now she is omission biased in the sense that she refuses to decide (and declares each defendant not-guilty).

\section{Conclusion}

Mechanism design theory has been extremely useful for the economic analysis of law (Baird, Gertner, and Picker 1998). This theory models a decision maker who designs the rules

\footnotetext{
${ }^{5}$ If $\alpha=10$, the KG model proposes the prosecutor to signal a .91 probability of guilt and the outcome further decreases to $34 \%$ of the defendants being declared guilty.
} 
of a game that maximizes her payoff while the participating agents are endowed with private information. Among the prominent applications to law and economics we mention contract law, liability, and tort. Recently, economic theory has reversed the setting by studying environments where the rules of the game are beyond the decision maker's control. Now, she can commit to a scheme releasing the information that the agents possess. This literature goes as Bayesian persuasion. Bergemann and Morris (2016) compare the two tracks in the literature: mechanism design versus Bayesian persuasion.

The present note appeals to the Bayesian persuasion approach and argues that the initial setup $(\mathrm{KG})$ conflicts with the traditions of criminal law. More precisely, the initial KG model entails a gap between the ex ante position (or prior) and the ex post position (or outcome). In the framework of repeated games or long term relationships, rational players do take the realizations into account (and not only the expected realizations). We stay in the Bayesian persuasion model and modify the preferences of the judge in the spirit of Blackstone's ratio. As such, we arrive at a more sustainable outcome.

Finally, and classified as a subject for future research, the classic analysis of internalizing externalities better known as the Coase theorem could be pursued. After all, the prosecutor inflicts disutility on both the judge and the subjects in the system, and at least the judge could bargain with the prosecutor to reduce his tendency to maximize the number of convictions. Since the prior distribution of guilty defendants is common knowledge, this would boil down to a problem of bargaining in the absence of asymmetric information, which given the state of knowledge is not too difficult a task. Unfortunately, the analysis shows that the judge hardly has a threatpoint in this negotiation process by dismissing the case (Subsection 4.2). Perhaps we should rely on judges with a commission bias and a dislike for convicting-innocent errors (Subsection 4.1).

\section{References}

Aghion P and P Bolton, 1992. Contracts as a Barrier to Entry, American Economic Review 77: 388-401.

Baird D, R Gertner, and R Picker, 1998. Game Theory and the Law, Harvard University Press.

Bergemann D and S Morris, 2016. Information Design, Bayesian Persuasion, and Bayes Correlated Equilibrium, American Economic Review 106(5): 586-591. 
Clark JR and DR Lee, 1996. Sentencing Laffer Curves, Political Myopia, and Prison Space, Social Science Quarterly 77(2): 245-255.

de Keijser Jan W, Evianne GM de Lange, and Johan A van Wilsem, 2014. Wrongful convictions and the Blackstone ratio: An empirical analysis of public attitudes, Punishment and Society 16(1): 32-49.

Fallon Richard H Jr, 2008. The Core of an Uneasy Case for Judicial Review, Harvard Law Review 121: 1693-1706.

Kamenica E and M Gentzkow, 2011. Bayesian Persuasion, American Economic Review 101(6): 25902615.

Laudan Larry, 2006. Truth, Error, and Criminal Law: An Essay in Legal Epistemology, Cambridge University Press.

McDougall C, MA Cohen, R Swaray, and A Perry, 2003. The Costs and Benefits of Sentencing: a Systematic Review, The Annals of the American Academy of Political and Social Science 587(1): $160-177$. 
Copyright @ 2018 @ the author(s). Discussion papers are in draft form. This discussion paper is distributed for purposes of comment and discussion only. It may not be reproduced without permission of the copyright holder. Copies of working papers are available from the author. 